\title{
What Is New in Critical Congenital Heart Defects?
}

\author{
Krisztina Kádár ${ }^{1,2}$ \\ ${ }^{1}$ Semmelweis University, Budapest, Hungary \\ ${ }^{2}$ Pediatric Cardiac Centre, Gottsegen Hungarian Institute of Cardiology, Budapest, Hungary
}

Congenital heart defects (CHD) are the most common birth defects and result in significant morbidity worldwide. Critical CHD are neonatal cardiovascular emergencies that require medical and surgical treatment early after birth.

The area of Pediatric Cardiology has experienced a huge progress lately, due to advances in diagnostic and therapeutic approaches. However, echocardiography remains the gold standard in the diagnosis and follow-up of patients with critical CHD.

\section{FETAL ECHOCARDIOGRAPHY}

Fetal echocardiography has been identified lately as a powerful technique for the diagnosis of CHD. Liu $\mathrm{H}$ et al. have demonstrated in a meta-analysis that the sensitivity of this technique to identify CHD increases to $77.1 \%$ for extensive fetal echocardiographic examination, and the specificity of the method is quite favorable (99.9\%). ${ }^{1}$

Prenatal diagnosis of CHD has a huge impact on postnatal management and outcome. Several echocardiographic parameters and indexes have been identified to predict the certain postnatal outcome and the proper management, especially in critical CHD such as aortic coarctation, pulmonary atresia with intact ventricular septum, transposition of the great arteries, hypoplastic left heart syndrome, a.s.o. ${ }^{2-5}$

Also, the development in ultrasonography technology and fetal interventional techniques allows intrauterine treatment of several CHDs. Complex techniques, such as fetal balloon valvuloplasty for severe aortic stenosis, or severe pulmonary stenosis with intact ventricular sep- tum, have been described. Also, atrial septoplasty or stent placement were attempted for a restrictive atrial septum in fetuses with hypoplastic left heart syndrome. ${ }^{6}$

\section{POSTNATAL ECHOCARDIOGRAPHY}

The role of echocardiography in the management of different critical CHD is greatly emphasized. Some authors have underlined the role of tricuspid valve $\mathrm{z}$ score as a predictor of outcome in neonates with pulmonary atresia with intact ventricular septal defect.7,8

Others have described some compound indexes, such as the carotid-subclavian index, an isthmus/ductus ratio with diagnostic value in neonatal aortic coarctation. ${ }^{9-11}$

In the current issue of JCE, a study by Muntean et al. ${ }^{12}$ addresses an important topic related to the role of echocardiography in neonatal cardiovascular emergencies, namely in simple transposition of the great arteries. Inadequate intercirculatory mixing is a fatal condition in such patients, the restrictive interatrial communication being the most important cause of this condition. Balloon atrial septostomy (BSA) is mandatory in such patients in order to create a nonrestrictive atrial septal defect (ASD).

So far, only a few study have assessed the echocardiographic features of inadequate intercirculatory mixing by measuring the ASD size or peak/mean gradient of flow through the interatrial communication, but for now there is no consensus in the literature. ${ }^{13-16}$

Thus, Muntean's study is valuable, as it aims to identify some compound parameters that can predict inadequate mixing in neonates with simple transposition of the great 
arteries. Interestingly, the results of the paper indicate three new compound echocardiographic parameters: the LA/RA ratio, the ASD diameter/(LA:RA ratio), and the ASD peak gradient/ASD diameter. According to the study, ASD diameter/(LA:RA ratio) with a cut-off value of 2.58 seems to be the best predictor of inadequate mixing and for BSA requirement in simple TGA patients.

\section{SPECKLE-TRACKING ECHOCARDIOGRAPHY}

Speckle-tracking echocardiography is a new echocardiographic method that allows the study of myocardial deformation. In the last few years, the utility of speckletracking echocardiography has been proved in childhood in left ventricular assessment in chemotherapy toxicity, muscular dystrophy, hypertrophic cardiomyopathy, end-stage renal disease, obesity, right ventricular assessment in pulmonary arterial hypertension, cardiac dyssynchrony etc. ${ }^{1-21}$ So far, in pediatric heart disease, strain imaging is considered a research tool, but it will soon play an important role in clinical practice, just like in adults.

\section{D ECHOCARDIOGRAPHY}

3D echocardiography has become also important in the management of CHD. Recent guidelines recommend using 3D echocardiography to guide catheter-based interventions in children, such as ASD closure or VSD closure, or to measure ventricular volumes and the ejection fraction. ${ }^{22}$ However, the actual implementation into clinical practice, according to Simpson et al., is questioned by the paucity of normal data in childhood.

\section{NEW TRENDS IN GENETICS}

The genetic diagnosis of the CHD has also experienced a huge progress in the last years. However, the etiology of the majority of cardiovascular defects remains unknown, genetic, epigenetic, or environmental factors being recognized as playing an important role. Regarding genetic factors, new technologies are applied lately such as single nucleotide polymorphism (SNPs), copy number variants, or next-generation sequencing. ${ }^{23-28}$

In conclusion, Pediatric Cardiology is a continuously evolving field of Cardiology. The most difficult part in pediatric echocardiographic evaluation is the lack of the normal data, as measurements have to be expressed relative to body size. Future studies are necessary in order to determine all normal data in pediatric patients.

\section{REFERENCES}

1. Liu H, Zhou J, Feng QL, et al. Fetal echocardiography for congenital heart disease diagnosis: a meta-analysis, power analysis and missing data analysis. Eur J Prev Cardiol. 2015;22:1531-1547. doi: 10.1177/2047487314551547.

2. Familiari A, Morlando M, Khalil AA, et al. Risk factor for coarctation of the aorta on prenatal ultrasound: a systemic review and meta-analysis. Circulation. 2017;136:24. https:// doi.org/10.1161/CIRCULATIONAHA.116.024068.

3. Mărginean C, Mărginean CO, Muntean I, Togănel R, Voidăzan S, Gozar L. The role of ventricular disproportion, aortic and ductal isthmus ultrasound measurements for the diagnosis of fetal aortic coarctation, in the third trimester of pregnancy. Med Ultrason. 2015;17:475-481. doi: 10.11152/ mu.2013.2066.174.rvd.

4. Peterson RE, Levi DS, Williams RJ, Lai WW, Sklansky MS, Drant S. Echocardiographic predictors of outcome in fetuses with pulmonary atresia with intact ventricular septum. J Am Soc Echocardiogr. 2006;19:1393-1400. doi: 10.1016/j. echo.2006.05.021.

5. Salvin JW, McElhinney DB, Colan SD, et al. Fetal tricuspid valve size and growth as predictors of outcome in pulmonary atresia with intact ventricular septum. Pediatrics. 2006;118:e415-e420. doi: 10.1542/peds.2006-0428.

6. Moon-Grady AJ, Morris SA, Belfort M, et al. International Fetal Cardiac Intervention Registry: A Worldwide Collaborative Description and Preliminary Outcomes. JACC 2015;66:388399. doi: 10.1016/j.jacc.2015.05.037.

7. Alwi M. Management algorithm in pulmonary atresia with intact ventricular septum. Catheter Cardiovasc Interv. 2006;67:679-686. doi: 10.1002/ccd.20672.

8. Suteu CC, Muntean I, Benedek T, Togănel R. Giant dissecting ventricular septal haematoma associated with critical congenital heart disease. Interactive cardiovascular and thoracic surgery. 2016;23:837-838. doi: 10.1093/icvts/ivw223.

9. Dodge-Khatami A, Ott S, Di Bernardo S, Berger F. Carotidsubclavian artery index: new echocardiographic index to detect coarctation in neonates and infants. Ann Thorac Surg. 2005;80:1652-1621. doi: 10.1016/j.athoracsur.2005.04.041.

10. Mivelaz Y, Di Bernardo S, Meijboom EJ, Sekarski N. Validation of two echocardiographic indexes to improve the diagnosis of complex coarctations. Eur J Cardiothorac Surg. 2008;34:10511056. doi: 10.1016/j.ejcts.2008.07.036.

11. Lu CW, Wang JK, Chang CI, et al. Noninvasive diagnosis of aortic coarctation in neonates with patent ductus arteriosus. J Pediatr. 2006;148:217-221. doi: 10.1016/j.jpeds.2005.09.036.

12. Muntean I, Toma D, Togănel R. Predictors of Inadequate Mixing in Transposition of the Great Arteries - a Critical Neonatal Condition. Journal of Cardiovascular Emergencies. 2017;3:181-187. doi: 10.1515/jce-2017-0024.

13. Graziano JN, Heidelberger KP, Ensing GJ, Gomez CA, Ludomirsky A. The influence of a restrictive atrial septal defect on pulmonary vascular morphology in patients with hypoplastic left heart syndrome. Pediatr Cardiol. 2002;23:146151.

14. Canter CE, Moorehead S, Huddleston CB, Spray TL. Restrictive atrial septal communication as a determinant of outcome of cardiac transplantation for hypoplastic left heart syndrome. Circulation. 1993;88:II456-II460. 
15. Dash PK, Satpathy M. Atrial septal defect (secundum type). In: Sathpathy M, Mishra BR. Clinical Diagnosis of Congenital heart disease. Jaypee/The Health Sciences Publisher/New Delhi, 2015; p. 76-84.

16. Kuhn MA, Larsen RL, Mulla NF, Jofnston JK, Chinnock RE, Bailey LL. Outcome of infants with hypoplastic left heart syndrome who undergo atrial septostomy before heart transplantation. Am J Cardiol. 2000;85:124-127.

17. Pignatelli RH, Ghazi P, Reddy SC, et al. Abnormal Myocardial Strain Indices in Children Receiving Anthracycline Chemotherapy. Pediatr Cardiol. 2015;36:1610-1616. doi: 10.1007/s00246-015-1203-8.

18. Jo WH, Eun LY, Jung JW, Choi JY, Gang SW. Early Marker of Myocardial Deformation in Children with Duchenne Muscular Dystrophy Assessed Using Echocardiographic Myocardial Strain Analysis. Yonsei Med J. 2016;57:900-904. doi: 10.3349/ ymj.2016.57.4.900.

19. Van Huis M, Schoenmaker NJ, Groothoff JW, et al. Impaired longitudinal deformation measured by speckle-tracking echocardiography in children with end-stage renal disease. Pediatr Nephrol. 2016;31:1499-1508. doi: 10.1007/s00467016-3362-0.

20. Muntean I, Benedek T, Melinte M, Suteu C, Togănel R. Deformation pattern and predictive value of right ventricular longitudinal strain in children with pulmonary arterial hypertension. Cardiovasc Ultrasound. 2016;14:27. doi: 10.1186/ s12947-016-0074-3.

21. Barbosa JA, Mota CC, Simoes E, Silva AC, Nunes MC, Barbosa $M M$. Assessing pre-clinical ventricular dysfunction in obese children and adolescents: the value of speckle tracking imaging. Eur Heart J Cardiovasc Imaging. 2013;14:882-889. doi: 10.1093/ehjci/jes294.

22. Simpson J, Lopez L, Acar P, et al. Three-dimensional Echocardiography in Congenital Heart Disease: An Expert Consensus Document from the European Association of Cardiovascular Imaging and the American Society of Echocardiography. J Am Soc Echocardiogr. 2017;30:1-27. doi: 10.1016/j.echo.2016.08.022.

23. Richards AA, Garg V. Genetics of congenital heart disease. Curr Cardiol Rev. 2010;6:91-97. doi: 10.2174/157340310791162703.

24. Muntean I, Togănel R, Benedek T. Genetics of Congenital Heart Disease: Past and Present. Biochem Genet. 2017;55:105123. doi:10.1007/s10528-016-9780-7.

25. Kuehl K, Loffredo C, lammer EJ, Iovannisci DM, Shaw GM. Association of Congenital Cardiovascular Malformations With 33 Single Nucleotide Polymorphisms of Selected Cardiovascular Disease-Related Genes. Birth Defects Res A Clin Mol Teratol. 2010;88:101-110. doi: 10.1002/bdra.20630.

26. Togănel R, Muntean I, Duicu C, Făgărăşan A, Gozar L, Bănescu $\mathrm{C}$. The role of eNOS and AGT gene polymorphisms in secondary pulmonary arterial hypertension in Romanian children with congenital heart disease. Rev Romana Med Lab. 2013;21:267274. doi: 10.2478/rrlm-2013-0031.

27. Postma AV, Bezzina CR, Christoffels VM. Genetics of congenital heart disease: the contribution of the noncoding regulatory genome. J Hum Genet. 2016;61:13-19. doi: 10.1038/jhg.2015.98.

28. Smith T, Rajakaruna C, Caputo M, Emanueli C. MicroRNAs in congenital heart disease. Ann Transl Med. 2015;3:333. doi: 10.3978/j.issn.2305-5839.2015.12.25. 